\title{
Relationships between two kinds of MSP in China
}

\author{
Honghao Tang \\ College of Oceanic and Atmospheric Science, \\ Ocean University of China-Laoshan Campus, Qingdao, China \\ Qi Yue \\ National Ocean Technology Center, Tianjin, China \\ Chen Wang \\ Oceanic Consultation Center, \\ Ministry of Natural Resources of the People's Republic of China, Beijing, China \\ Lingling Zhou \\ College of Oceanic and Atmospheric Science, Ocean University of China, \\ Qingdao, China \\ Jing $\mathrm{Yu}$ \\ College of Oceanic and Atmospheric Science, Ocean University of China, \\ Qingdao, China and \\ Institution of Marine Development of Ocean University of China, Qingdao, China \\ Wen $\mathrm{Wu}$ \\ College of Oceanic and Atmospheric Science, Ocean University of China, \\ Qingdao, China \\ Ruoyan Feng \\ Qingdao Marine Science and Technology Achievements Promotion Center, \\ Qingdao Municipal Marine Development Bureau, Qingdao, China, and \\ Chen Ma \\ College of Oceanic and Atmospheric Science, Ocean University of China, \\ Qingdao, China
}

\begin{abstract}
Purpose - The major marine functional zoning plan (MMFZP) and marine functional zoning (MFZ) are two important kinds of marine spatial planning (MSP) in China. Their developing and implementation are integral to rational marine utilization and sustainable marine development. The purpose of this research is to study how these two kinds of MSP work in coordination in China.

Design/methodology/approach - This paper reviewed the present status of MSP research in China and abroad and presented a comparative study of the MMFZP and MFZ from different aspects, analyzing the relationship between the two.
\end{abstract}

C Honghao Tang, Qi Yue, Chen Wang, Lingling Zhou, Jing Yu, Wen Wu, Ruoyan Feng and Chen Ma. Published in Marine Economics and Management. Published by Emerald Publishing Limited. This article is published under the Creative Commons Attribution (CC BY 4.0) licence. Anyone may reproduce, distribute, translate and create derivative works of this article (for both commercial and noncommercial purposes), subject to full attribution to the original publication and authors. The full terms of this licence may be seen at http://creativecommons.org/licences/by/4.0/legalcode

Conflict of interest: The authors declare that they have no conflict of interest

This study was financially supported by the NSFC-Shandong Joint Fund (No. U1706215).
Marine spatial planning

Received 4 December 2019 Revised 13 September 2020 Accepted 21 September 2020 
MAEM

3,1

Findings - The study found obvious differences between the MMFZP and MFZ, with respect to their concept and connotation, purpose and goal, as well as zoning methods and zoning functions. MFZ provides reference with respect to data, zoning methods and partial zoning results for the MMFZP, which in turn takes measures for addressing issues faced by MFZ and promotes the national MSP work.

Originality/value - In the process of developing and implementing the two zoning plans, this paper emphasizes the necessity to strengthen data sharing, reference of zoning techniques and coordination in zoning work, which will help to improve China's marine spatial management.

Keywords Marine spatial planning (MSP), Major marine functional zoning plan (MMFZP), Marine functional zoning (MFZ), Comparative study

Paper type Research paper

\section{Introduction}

Marine spatial planning (MSP) is an effective tool for resolving conflicts between various human activities and marine ecological protection work. It is also an effective means for multipurpose marine management (Zhang, 2011). The major marine functional zoning plan (MMFZP) and marine functional zoning (MFZ) are two important kinds of MSP frameworks that are being presently implemented in China.

In March 2006, the 11th Five-Year Plan for National Economic and Social Development of the People's Republic of China proposed that "According to the carrying capacity of resources and environment, existing development density and potential, future population distribution, economic layout, land use and urbanization pattern, the territorial space of China should be divided into four kinds of major functional areas. That is, optimized development areas, key development areas, restricted development areas and prohibited development areas." In August 2015, the State Council issued the MMFZP, which reflects China's national strategy for major functional areas in the marine space.

Based on location, natural resources, environmental conditions and development requirement of the marine area, $\mathrm{MFZ}$ determines the dominant function of the marine area and divides it into different types of marine functional areas. The work of MFZ started in 1988. So far, China has carried out three large-scale MFZ works. On March 3, 2012, the State Council formally approved the latest version of MFZ - MFZ (2011-2020) - and kick started its implementation.

In this paper, we shall first summarize the national and international statuses of research on MSP. We shall also draw a comparison between the MMFZP and MFZ, conduct a multisided study on the relationships between them and offer suggestions on their development and implementation. This study aims at providing references for scientific developing, reasonable implementation and effective cooperation between the MMFZP and MFZ to ensure the rational use of marine space and promote the sustainable development of marine areas.

\section{The status of global research on marine spatial planning}

\subsection{Global practice of marine spatial planning}

During recent years, various countries have started to use MSP or ocean zoning to reduce conflicts and use coastal and marine resources more sustainably. There are approximately 60 MSP processes that have been completed or are currently underway globally (Fletcher et al., 2013).

The initial concept of MSP and one of its primary tools, ocean zoning has attracted the attention of international and national governments and nongovernmental organizations in developing marine protected areas (MPAs). More recent attention has been placed on planning and managing multiple uses of marine space, particularly in areas where use conflicts are already well known and specified. In various countries, MSP concepts are being 
used as a first step to make ecosystem-based management a reality (Intergovernmental Oceanographic Commission, 2017).

\subsection{The status of foreign research on marine spatial planning}

MSP aims to resolve the conflict between exploitation of the sea and marine environmental protection. It originated from the demand of the international community to strengthen the management of MPAs. In November 2006, the United Nations Educational, Scientific and Cultural Organization (UNESCO) held its first symposium on MSP and made it clear that the developing and implementation of MSP based on ecosystems should be carried out in order to regulate marine utilization and protect marine ecology. Since then, the research study on MSP based on ecosystem is being carried out internationally. These studies focus on theories and technical systems of MSP.

These MSP theories mainly involve ecosystem-based management, multiobjective planning and socioeconomic evaluation. For example, reviewing the key elements of existing MSP frameworks, ecosystem management, fisheries and conservation frameworks. Dunstan et al. (2016) proposed an adaptive hierarchical approach for these elements and studied how ecologically or biologically significant marine areas (EBSA) can be used to support this approach. Based on an empirical study of the MSP process in Germany, Stephen Jay et al. explored several important issues in the application of the ecosystem approach (EA) in MSP: (1) issues related to deterministic and relativistic views of the ecosystem, (2) the subsequent role of MSP in prioritizing ecological imperatives or balancing competing interests and (3) the integration of socioeconomic activities into the marine environment (2016). E Domínguez-Tejo et al. reviewed the practical work accomplished for ecosystembased marine spatial zoning over the past decade and highlighted two management issues: how social, economic and environmental values were integrated into the spatial planning analysis and how cross-realm connectivity was addressed by planning teams (2016).

The research content of the technical system includes definition of time and space in planning identification of marine ecological conditions and utilization status and the mode of stakeholders' participation. As a new effective tool, a geographic information system (GIS) is widely applied in the MSP technology system. For example, the Philippines has developed a decision support tool named PhilSHORE, which is based on the GIS platform. To provide data support for MSP, the GIS facilitates collection, storage, processing, analysis and display of geospatial data (Ang et al., 2015). In the meanwhile, Antje Gimpel et al. combined GIS and multi-criteria evaluation (MCE) techniques to index suitable co-sites in the German exclusive economic zone of the North Sea. The GIS modeling framework proved to be powerful in defining potential co-location sites (Gimpel, 2015). Moreover, Strickland-Munro et al. presented a new approach to MSP, whereby they used online the public participation GIS (PPGIS) to provide social data for the construction of large marine parks (2016).

However, these foreign studies on MSP still have some shortcomings: the social demand for sea use has not been quantitatively analyzed, there are few mature methods which resolve conflicts related to sea use and enhance the compatibility of sea areas and predictions for marine ecological environment are unsatisfactory.

\subsection{The status of domestic research on marine spatial planning}

The MSP work started in China with the advent of MFZ in 1989, while the MMFZP kicked off in 2006 and has been in process ever since. In China, immense research efforts have been made in these two kinds of MSP frameworks.

Presently, "MSP based on ecosystem" is a hot area for research in China. From the perspective of marine environmental protection, Quanming Wang et al. analyzed the shortcomings of current MFZ and proposed suggestions (2016b). Setting Quanzhou sea area
Marine spatial planning

3


MAEM

3,1

4

as a sample, Jianji Liao studied the methodology of selecting important marine eco-function areas and identified nine types of potentially important marine eco-function areas (2015). In view of the obvious economic orientation and lack of ecological security orientation in MFZ, Yuan Lv proposed optimizing the content and process of MFZ from the perspective of enhancing marine ecological security (2015).

As domestic scholars continue to come up with new research achievements, zoning technology has become an important part of MSP in recent years. Ning Wang et al. found that there was inconsistency and ambiguity between the classification system of the national and the provincial MFZ. And the coding method should be optimized as well (2016a). Quanming Wang et al. summarized the system of sea area division of new round of national and provincial MFZs. Furthermore, they suggested increasing the quantitative analysis basis of sea area division and boundary delimitation (2014).

Domestic scholars have also made a comparative study of MSP at home and abroad, pointing out some current problems. MFZ focuses on the management of sea use for construction projects, while ecological protection is ignored. Too many reclamation projects supported by MFZ caused increasingly serious ecological and environmental problems (Yu et al., 2019), such as sharp decrease of the tidal-flat area. On the other hand, ecosystem-based management has not been fully implemented in China's MSP. Due to the lack of marine biogeographic data in China, the boundaries of spatial units are blurred, the degree of protection is misjudged and the management objectives are difficult to quantify (Hu et al., 2020). In addition, compared with foreign countries, the degree of public participation in China's MSP is relatively low. The top-down government decision-making plays a leading role in the planning. However, it ignores that marine space is the "public space" for human beings to engage in sea use activities (Di and Han, 2019). As for the relationship between the MMFZP and MFZ, the domestic scholars had done some research studies before the latest version of MFZ was published. As two kinds of MSP in China, although the MMFZP and MFZ work closely, yet they have obvious differences with respect to their classification, connotation and functional orientation. The MMFZP is an important foundation and basis of MFZ. And MFZ is the concrete implementation and functional refinement of the MMFZP in marine space (Fu and Shen, 2008). Based on the overall situation of national development, the MMFZP is a zoning work of the national strategic level. On the other hand, MFZ aims at guiding specific marine development activities, based on the actual situation of a specific sea area (Wang and Guo, 2009). However, these research studies mainly involve the concept, connotation and functions of the MMFZP and MFZ, while offering some prediction for their implementation. In this backdrop, this paper sums up the developing and implementation work of the MMFZP and MFZ, studies the differences and relationships between them and proposes some suggestions for enhancing coordination and carrying out upgrade.

\section{Differences between marine functional zoning and the major marine functional zoning plan}

Although the timing and location of MFZ and the MMFZP may overlap, yet there are significant differences between the two, mainly in the following aspects (Table 1):

\subsection{The concept and connotation}

In accordance with the carrying capacity of marine environment and resources, existing development density and development potential, the MMFZP spatially classifies national marine areas as per their state of development into four categories. It includes optimized, key, restricted and prohibited development areas. It takes into account marine resources and environment, degree of sea area development and utilization, level of marine economic 
development, economic strength and urbanization pattern, marine science and technology innovation ability, national strategic choice and other important elements. Major MFZ is also a process to specify the corresponding safeguards, regulate the development of marine space order and form a reasonable marine space development structure (State Oceanic Administration of China, 2011). Different from the functional zones with small area scope and simple functions, the major functional zone does not completely exclude other auxiliary and subsidiary functions (Zhang, 2011). Thus, the MMFZP is a more comprehensive and macro-level marine development plan that gives the sea area three major functions: construction of industries, cities and towns, agriculture and fishery production and ecological services. It has solved the problem of how to play the major function of the sea area scientifically and effectively.

The marine functional zone is a designated area with optimal functionality for sustainable socioeconomic development of countries/regions. Based on natural resources, environmental aspects, geographic location, development and utilization status, the marine functional zone is selected as the smallest functional unit of MFZ (Fu and Shen, 2008). MFZ is a basic framework to provide scientific basis for marine development, protection and management after dividing marine areas or islands into different types of marine functional zones. MFZ (2011-2020) divided marine areas into ten kinds of basic functional zones: agricultural and fishing, port shipping, industrial and urban, mineral and energy, tourism and leisure, marine protected, special utilization and reserved zones. It also put forward the development priorities and environmental protection requirements of each functional zone. In short, MFZ defines the dominant function and utilization scope of the marine area. It has facilitated responsible use of marine resources and protection of marine ecology.

\subsection{The purpose and goal}

The purpose of major MFZ is to build a coordinated, harmonious and sustainable marine land space pattern, so as to achieve sustained growth of the marine economy, narrow the gap between urban and rural areas, enhance the ability of sustainable development and improve regional comprehensive competitiveness. The MMFZP was proposed to principally outline major functional areas by 2020 and set some main objectives, such as forming a clear and rational pattern for utilization of ocean space, improving the efficiency of marine space utilization and enhancing the capacity of sustainable development of marine ecology. Major MFZ is a framework at the level of national marine development strategy. It has a more macroscopic and binding purpose as compared with MFZ.

In the meanwhile, the purpose of MFZ is to thoroughly implement the concept of scientific development, rationally exploit and utilize marine resources, protect and improve marine ecology, improve comprehensive marine management and control capabilities, establish a marine development and utilization order, achieve rational development and sustainable use of the marine area, so as to meet the national socioeconomic development needs. MFZ (2011-2020)

\begin{tabular}{lll}
\hline Differences & MFZ & MMFZP \\
\hline Concept & $\begin{array}{l}\text { More comprehensive and a macro-level } \\
\text { marine development plan }\end{array}$ & $\begin{array}{l}\text { Aim to define the dominant function and } \\
\text { utilization scope of the marine area }\end{array}$ \\
Purpose & $\begin{array}{l}\text { Building a coordinated, harmonious and } \\
\text { sustainable marine land space pattern }\end{array}$ & $\begin{array}{l}\text { Establishing a marine spatial development } \\
\text { and utilization order }\end{array}$ \\
Zoning & $\begin{array}{l}\text { Based on the carrying capacity of both marine } \\
\text { environment and resources, existing } \\
\text { method }\end{array}$ & $\begin{array}{l}\text { Based on natural attributes, exploitation and } \\
\text { utilization status and environmental }\end{array}$ \\
& development density, development potential & protection status of the ocean area
\end{tabular}

Main Adjusting the layout and degree of marine function development space

\section{Marine spatial planning}


MAEM

3,1

was proposed to achieve the main goal by 2020 , i.e. to employ scientific and strict implementation of $\mathrm{MFZ}$ for enhancing the role of sea area management in macro-control, improving marine ecological environment, expanding MPAs, maintaining the basic stability of fishery areas, strengthening the conservation of marine biological resources, controlling the scale of land reclamation, retaining marine reserve space resources and carrying out marine and coastal renovation and remediation. In conclusion, $\mathrm{MFZ}$ aims to provide an important basis for the development of marine management, such as sea-related policies, planning, marine management and marine environmental protection, while guiding marine exploitation and utilization activities.

\subsection{Zoning methods}

The division of major MFZ is a process of selecting a range of sea space as the evaluation unit and then using an index system to evaluate and form the major functional zoning of the ocean area. This index system is based on the carrying capacity of both marine environment and resources, existing development density, development potential and national marine strategy. The main steps of major MFZ include (1) confirming the prohibited development areas, (2) selecting the evaluation unit, (3) using the index system to calculate and evaluate the evaluation unit, (4) determining the type of marine major function area and (5) forming a major MFZ program (State Oceanic Administration of China, 2011).

Considering the national macro-control policies and coastal development strategies, the division of MFZ is based on natural attributes, exploitation and utilization status and environmental protection status of the ocean area. It is a process of reasonably defining the dominant function and use range of marine space resources. The main steps of MFZ include (1) determining all the functional types of each area according to natural attributes, (2) analyzing and comparing the functions of multifunctional areas to determine the dominant function and (3) comparing the dominant function (single function) with status quo of development and planning and then coordinating and forming the program of MFZ (State Oceanic Administration of China, 2006).

\subsection{The zoning function}

Major MFZ is about adjusting the layout and degree of marine development space. By optimizing, focusing, restricting and prohibiting development, it strengthens constraint on the approval of marine projects, thereby giving full play to the major function of the sea area. As a comprehensive and macroscopic marine development plan, the MMFZP has high social demand, mainly for management of sea use, marine environmental protection, island exploitation and utilization management, marine planning management and marine laws and regulations.

In the meanwhile, MFZ has been formed to establish a code of conduct for integrated marine management, providing the basis for both marine management and environmental protection and ensuring sea security for national socioeconomic development. At the same time, MFZ is not only a scientific basis for the use of sea but also the scientific standard of marine administrative organs for sea-use approval. Moreover, it also establishes a coordination mechanism for resolving sea-use conflicts between the government and different industries. From the point of view of marine utilization and protection, MFZ is determined by its leading function. As the basis for sea-use approval, it has a specific functional orientation of the ocean area.

\section{The relationship between marine functional zoning and the major marine functional zoning plan}

According to opinions of the State Council on the compilation of the National Major Functional Zoning Plan, major functional zoning is the fundamental basis of MFZ in space development 
and layout. At the same time, the developing and implementation of the MMFZP and MFZ are not carried out independently. Their relationship can be explained by the following two aspects:

\subsection{Marine functional zoning provides reference for the major marine functional zoning plan}

The MFZ work is being carried out since 1980s and MFZ (2011-2020) was completed in 2011. The work on major functional zoning started in 2006, while the MMFZP was issued by the State Council in August 2015. Given its early advent, MFZ can provide reference for the MMFZP in terms of data, zoning method and partial zoning result.

4.1.1 Reference to data. The MFZ work is based on a large amount of data, including natural environment information, resources development and utilization data, natural disasters and protection data, data of special zones, such as protected area and socioeconomic data and related planning. These data give a relatively detailed description of natural resources, development status and ability and the socioeconomic status of the ocean area.

The MMFZP is also a zoning work with a large scale, complex content and huge workload. The data, on which the MMFZP is based, overlap with MFZ. Therefore, considering the availability of the data, we can make full use of data that have been used in MFZ, so as to curb duplicate data collection and improve zoning efficiency. Moreover, timely replenishment of data is necessary when the data are missing or invalid (Wang, 2008).

4.1.2 Reference to zoning methods. The division of MFZ is mainly based on the index method. It involves dividing the ocean into different marine functional areas as per marine functional area classification and index systems, while taking into account natural and social attributes and environmental protection requirements of different regions. The index method is also applicable to the MMFZP. The MMFZP is based on a complete evaluation index system and its corresponding calculation and evaluation. It complies with the application and development of the index method.

In the MFZ framework, in order to determine the primary and secondary relationships between the type and function of the marine functional area, the comprehensive analysis method is used to coordinate the relationships of various sea-use types, taking into account the natural and social attributes and environmental protection requirements of the sea area. In the MMFZP, the major marine functional areas should also be determined according to various indexes. Making full use of the comprehensive analysis method, this determination is mainly based on the matrix discriminant method, while the index comprehensive evaluation and the key index determination methods are supplemented.

The GIS has embodied its value in MFZ, such as the application of GIS in the overlay analysis of multiple index elements. At present, the application of the web geographic information system (WebGIS) and the PPGIS in MSP has also become a hot topic for international research. Thus, it is particularly important to make the GIS an important support technology for the MMFZP by summarizing and drawing on the results of applied research.

4.1.3 Direct application of partial zoning results. MFZ (2011-2020) has pointed out that MPAs were designed for protection of marine resources, environment and ecosystem, including marine nature reserves and special marine protection areas. The MMFZP has defined the prohibited development areas, such as nature reserves at all levels, islands on which territorial sea base point is located and so on. Therefore, the MPAs in MFZ can be directly incorporated into the prohibited development areas in the MMFZP.

\subsection{The major marine functional zoning plan actualizes the promotion and development of marine functional zoning}

The MMFZP is not only a national macro-control on the ocean exploitation and utilization but also a strategic arrangement of a marine space development pattern. Based on the carrying 
MAEM

3,1

8

capacity of marine environment and resources, existing development density, development potential and suitability and practicality of carrying out high-intensity and concentrated development, the MMFZP determines the direction and principles of oceanic development, so as to achieve the coordinated development of human, resources and the environment. MFZ is based on the natural attributes of a specific sea areas and takes into account social attributes to define the concrete function of the sea and guide the specific development and utilization activities along the sea area. Compared with the strategic MMFZP, MFZ is more fundamental and regional. Therefore, the MMFZP is a higher level of zoning than MFZ. The MMFZP should be an important foundation and basis of the compilation of MFZ, while MFZ should be the concrete implementation and functional refinement of the MMFZP in marine space.

Since the implementation of MFZ, it has made great contributions to the exploitation and utilization of ocean area and marine environment protection. It has continuously guided the development of China's social economy and the adjustment of marine industry layout. However, some problems have been exposed in the process of MFZ. In light of these problems, corresponding measures have been taken for the developing and implementation of the MMFZP, thereby improving the seriousness and scientific appeal of MFZ.

4.2.1 Reversing the project-oriented zoning trend. MFZ is the basis of scientific utilization of sea and the standard for marine administrative organs to examine and approve sea-use projects. An alteration in MFZ is submitted by the original compiling organization and the relevant department at the same level for approval. However, in the course of the implementation of $\mathrm{MFZ}$, it is relatively common to change $\mathrm{MFZ}$ in order to ensure the implementation of the sea-use project. It is so because of the inconsistency between the function of a sea-use project and MFZ. The frequent changes in MFZ have seriously damaged its seriousness as a basis for sea-use approval. However, as an important basis for the implementation of the National Ocean Development Strategy, the MMFZP is more stable and has played a binding role in formulating and implementing MFZ. Therefore, the projectoriented zoning trend has been reversed.

4.2.2 Coordinating zoning at borders of adjacent regions. In the work of MFZ, defining the basic function of the sea area based on the natural attribute is an important principle (Guan and $\mathrm{E}, 2013)$. The spatial entity unit with natural attributes is chosen as the basic unit of zoning, while the unit boundary is also considered. MFZ (2011-2020) divided the national ocean areas into 29 areas according to their natural attributes and then defined the leading function of each area.

However, provincial, municipal and county-level MFZ is carried out separately by marine administrative departments at various levels. Therefore, spatial entity units with natural attributes can be separated at the administrative boundary, which causes a lack of coordination with respect to $\mathrm{MFZ}$ among adjacent administrative regions.

Major MFZ takes overall consideration of the boundary of the administrative, natural and economic units. In order to facilitate the implementation of the administration and regional development policies, the MMFZP takes the current administrative unit as its minimum basic unit. At some regions, where there is a lack of specific homogeneity, the MMFZP appropriately breaks the administrative boundaries as its basic unit has much larger area in order to coordinate the zoning between adjacent administrative regions.

4.2.3 Incomplete zoning coverage. The scope of MFZ (2011-2020) includes internal waters, territorial sea, contiguous and exclusive economic zones, continental shelf and other sea areas. At present, the area of MFZ is mainly related to coastal and archipelagic waters and important resources development and utilization area. In the meanwhile, the marine utilization activities are mainly concentrated in the offshore area, which puts a heavy pressure on the resources and environment of the coastal areas. In order to alleviate the pressure in the coastal area and achieve reasonable utilization of the ocean space, the work of MFZ should be extended to other sea areas. 
The MMFZP work provides an opportunity for further development of MFZ. The MMFZP has included the exclusive economic zone and the continental shelf area, while its specific planning work is also being carried out. All these zoning works provide favorable conditions and specific basis for MFZ to advance to the far-reaching sea areas.

4.2.4 Quantification of the index system. The index system for MFZ still lacks quantification. The index of some functional areas is described only briefly and no quantitative indicators are given, which affects the rigor of MFZ. The MMFZP has selected 11 quantitative evaluation indexes, such as available marine resources, marine environmental quality and utilization level of sea area. Thus, the ocean is divided into major functional areas through the determination of weight coefficient and quantitative calculation of indexes. At the same time, the evaluation index framework becomes more scientific, which provides a reference for the improvement in the MFZ index system.

\section{Recommendations}

Being two kinds of MSP in China, the MMFZP and MFZ have a multiaspect relationship. Thus, in the process of formulating and implementing the two zoning works, it is necessary to strengthen coordination between them and achieve scientific division of labor and effective cooperation. For this reason, this paper makes the following recommendations:

\subsection{Strengthen data sharing}

MFZ has provided a large amount of data for the MMFZP due to its antecedent nature. However, in theory, the MMFZP is the fundamental basis of MFZ in marine space development and layout. Moreover, the MMFZP predicts the future development trend, such as social and economic development conditions and needs. In the future, the advanced MMFZP will provide a large number of natural environments, resource development and utilization and socioeconomic data for MFZ. MFZ will also obtain detailed data on natural conditions of the ocean in its specific implementation and functional refinement. In order to reduce data duplication in the process of data acquisition and improve the zoning efficiency, it is necessary to strengthen data sharing in the two zoning works.

\subsection{Strengthen mutual reference of zoning methods}

The MMFZP's zoning method is more macroscopic, while its evaluation index system is more systematic. While MFZ directs the sea-use program, its zoning method is more detailed and its evaluation index system is implemented to all kinds of sea use. In practical work, it is important to give full play to the major function of the ocean area and ensure the scientific and rational use of specific sea areas. Therefore, in the process of the developing of the two zoning methods, we should strengthen mutual referencing between zoning methods and play to their respective advantages, so that that they may to complement each other, cover up for each other's shortcomings and enhance their scientific appeal.

\subsection{Strengthen coordination between two zoning frameworks}

Given the relationship between the MMFZP and MFZ, the leading function of ocean area should be based on its major function. When there are significant differences between the MMFZP and MFZ on functional orientation of the marine area, we should coordinate the two zoning frameworks and guide the leading function of the sea area to meet the MMFZP needs. As two important bases for the management and approval of sea-use activities, the MMFZP and MFZ are implemented jointly. The communication between the implementation departments of the MMFZP and MFZ should be strengthened to detect and solve the problems. In addition, related departments should take measures to strengthen the 
MAEM

3,1 consultation and cooperation work for the MMFZP and MFZ in the areas of zoning modification and renovation.

\section{Conclusion}

This paper has mainly studied the differences and relationship between two important MSP frameworks in China, namely, the MMFZP and MFZ. After reviewing the domestic and foreign statuses of research on MSP, this paper has pointed out their deficiencies and analyzed the necessity of our research.

First, we analyzed the differences between the MMFZP and MFZ. By comparing the concept and connotation, purpose and goal, zoning methods and zoning function of the two, we pointed out their concrete differences. Second, we researched the relationships between the MMFZP and MFZ. For one thing, MFZ provides references with respect to data, zoning methods and partial zoning results for the MMFZP. For another, in view of the problem with MFZ - such as project-oriented zoning trend, uncoordinated zoning between adjacent regions, incomplete zoning coverage and lack of quantification in the index system - the MMFZP has taken corresponding measures in its implementation to promote the national MSP work. According to these research results, we have suggested to strengthen data sharing, referencing between zoning methods and coordination between the MMFZP and MFZ.

Scientific division of labor and effective cooperation between the MMFZP and MFZ can ensure science- and principle-based marine development, thereby achieving rational use of marine resources and effective protection of marine environment. On the national level, it has great significance for the sustainable development of China's marine environment and the construction of marine ecological civilization.

\section{References}

Ang, M.R.C.O., Panganiban, L.C.I.K., Mamador, C.B., Luna, O.D.G.D., Bausas, M.D. and Cruz, J.P. (2015), "PhilSHORE: development of a WebGIS-based marine spatial planning tool for tidal current energy resource assessment and site suitability analysis", World Academy of Science, Engineering and Technology, International Journal of Computer, Electrical, Automation, Control and Information Engineering, Vol. 9 No. 5, pp. 1143-1148.

Di, Q.B. and Han, X. (2019), "Review and prospects of marine spatial planning research in China from the perspective of territorial spatial planning", Journal of Ocean University of China (Social Sciences), Vol. 5, pp. 59-68, (in Chinese).

Dunstan, P.K., Bax, N.J., Dambacher, J.M., Hayes, K.R., Hedge, P.T., Smith, D.C. and Smith, A.D.M. (2016), "Using ecologically or biologically significant marine areas (EBSAs) to implement marine spatial planning", Ocean and Coastal Management, Vol. 121, pp. 116-127.

Fletcher, S., McKinley, E., Buchan, K.C., Smith, N. and McHugh, K. (2013), "Effective practice in marine spatial planning: a participatory evaluation of experience in Southern England", Marine Policy, Vol. 39, pp. 341-349.

$\mathrm{Fu}$, J.L. and Shen, F. (2008), "Discussion on the relationship between marine functional Zoning and major functional Zoning", Ocean Development and Management, Vol. 25, pp. 3-9, (in Chinese).

Gimpel, A., Stelzenmüller, V., Grote, B., Buch, B.H., FloEter, J., Riboni, I.N., Pogoda, B. and Temming, A. (2015), "A GIS modelling framework to evaluate marine spatial planning scenarios: Co-location of offshore wind farms and aquaculture in the German EEZ", Marine Policy, Vol. 55, pp. 102-115.

Guan, D.M. and E, D. (2013), Research on Marine Functional Zoning, China Ocean Press, Beijing, (in Chinese).

Hu, W.J., Chen, B., Ma, Z.Y., Yu, W.W., Xiao, J.M. and Zhang, D. (2020), "The research progress and enlightenment of ecosystem-based marine spatial planning", Ocean Development and Management, Vol. 37 No. 4, pp. 3-11, (in Chinese). 
Intergovernmental Oceanographic Commission (2017), "MSP around the globe", available at: http:// msp.ioc-unesco.org/world-applications/overview/ (accessed 3 December 2018).

Jay, S., Klenke, T. and Janßen, H. (2016), "Consensus and variance in the ecosystem approach to marine spatial planning: German perspectives and multi-actor implications”, Land Use Policy, Vol. 54, pp. 129-138.

Liao, J.J. (2015), "Methodology of Selecting Important Marine Eco-Function Areas - A Case Study in Quanzhou City", Working Paper, Third Institute of Oceanography, State Oceanic Administration, Xiamen, (in Chinese).

Lv, Y. (2015), "The study on related of marine function Zoning in China based on marine ecological security”, Working Paper, Ocean University of China, Qingdao, (in Chinese).

State Oceanic Administration of China (SOA) (2006), "Technical directives for the division of marine functional zonation (GB/T 17108-2006)", available at: http://www.doc88.com/p-9058157145114. html (accessed 26 August 2016).

State Oceanic Administration of China (SOA) (2011), "Technical regulation for division of marine major function oriented zone, (HY/T 146-2011)", available at: http://www.doc88.com/p9025159077478.html (accessed 11 December 2018).

Strickland-Munro, J., Kobryn, H., Brown, G. and Moore, S.A. (2016), "Marine spatial planning for the future: using public participation GIS (PPGIS) to inform the human dimension for large marine parks", Marine Policy, Vol. 73, pp. 15-26.

Tejo, E.D., Metternicht, G., Johnston, E. and Hedge, L. (2016), "Marine Spatial Planning advancing the ecosystem-based approach to coastal zone management: a review", Marine Policy, Vol. 72, pp. 115-130.

Wang, Q. (2008), The Study of Comparision and Relationship between the Division of Marine Functional Zones and the Division of Marine Main Functional Zones, Ocean University of China, Qingdao, (in Chinese).

Wang, Q. and Guo, P.F. (2009), "The study of relationship between the division of marine functional zones and the division of marine main functional zones", Transactions of Oceanology and Limnology, Vol. 4, pp. 188-192, (in Chinese).

Wang, Q.M., Ma, H.W., Fu, Y.B. and Li, B.Y. (2014), "Research on sea area division of marine functional Zoning", Marine Environmental Science, Vol. 33, pp. 472-476, (in Chinese).

Wang, N., Jia, J.J., Cai, T.L., Liu, Y.F., Xin, P. and Wang, Y.P. (2016a), "The classification system of marine functional zones", Ocean Development and Management, Vol. 12, pp. 76-81, (in Chinese).

Wang, Q.M., Jie, J., Li, B.Y. and Yu, M. (2016b), "Evaluation of marine functional Zoning based on marine environmental protection”, Ocean Development and Management, Vol. 12, pp. 72-75, (in Chinese).

Yu, Y.H., Wang, P., Wang, Q.M., Huang, J. and Zhao, B. (2019), "Marine reclamation in China: ecoenvironment problems and supervision suggestions", Environmental Protection, Vol. 47 No. 7, pp. 17-19, (in Chinese).

Zhang, R., Zhang, L.P. and Fang, Q.H. (2011), "Research progress of marine spatial planning and main function zoning", Ocean Development and Management, Vol. 28 No. 9, pp. 16-20.

\section{Corresponding author}

Jing Yu can be contacted at: by6801@ouc.edu.cn
Marine spatial planning 